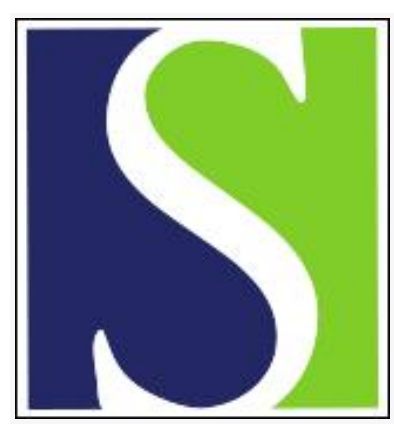

Scand J Work Environ Health 1997;23(6):440-449

https://doi.org/10.5271/sjweh.267

Issue date: Dec 1997

Task-based estimation of past exposures to 60-hertz magnetic and electric fields at an electrical utility

by Deadman J-E, Church G, Bradley C, Armstrong BG, Thériault G

Key terms: electric fields; electrical utilities; extremely low frequency; magnetic fields; retrospective exposure estimation

This article in PubMed: www.ncbi.nlm.nih.gov/pubmed/9476808 


\title{
Task-based estimation of past exposures to 60-hertz magnetic and electric fields at an electrical utility
}

\author{
by Jan-Erik Deadman, PhD, ${ }^{1}$ George Church, MSc, ${ }^{1,2}$ Chad Bradley, MSc, ${ }^{1,3}$ Ben G Armstrong, PhD, 1,4 \\ Gilles Thériault, $P h D^{1}$
}

\begin{abstract}
Deadman J-E, Church G, Bradley C, Armstrong BG, Thériault G. Task-based estimation of past exposures to 60hertz magnetic and electric fields at an electrical utility. Scand J Work Environ Health 1997;23(6):440-9.
\end{abstract}

\begin{abstract}
Objectives Past exposures of electric utility workers to extremely low-frequency (ELF) magnetic (B) and electric fields $(E)$ in Québec were estimated.

Methods The current intensities were measured and durations of exposures determined for tasks or work locations in 14 job categories. Past task or location intensities were extrapolated from the present on the basis of interviews with long-term workers and utility personnel. Past task or location durations were estimated for the long-term workers. Time-weighted average (TWA) exposures for past periods were reconstructed for jobs from the intensity and duration estimates.

Results Magnetic fields were estimated to have increased the most over time for substation and distributionline jobs. Magnetic field exposures for jobs in the generation and transmission of electricity were estimated to have increased very little. For substation jobs, the ratios of magnetic fields in 1945 to those in 1990 ranged from 0.42 to 0.69 ; the corresponding figures for distribution-line jobs ranged from 0.36 to 0.94 . For electric fields in substations, the estimated increase over time was less than for magnetic fields, the 1945:1990 ratios ranging from 0.59 to 0.88 . For the distribution line jobs, the 1945:1990 ratios for electric fields were less than 1.0 in 4 cases $(0.6$ to 0.89$)$, more than 1.0 in 3 others (1.13 to 2.01) and unchanged in 1 .

Conclusions Reconstruction of TWA exposures allowed changes in the intensity and the duration of exposures to be considered separately. Documentation of the intensity and duration of exposures for different tasks allows exposure reconstruction for jobs that have ceased to exist. The method is applicable elsewhere if exposure-monitoring records allow the level and duration of exposures for tasks or locations to be calculated and if estimates of past durations and intensities of exposures can be reliably obtained.
\end{abstract}

Key terms retrospective exposure estimation, extremely low frequency, magnetic fields, electric fields, electrical utilities.

Retrospective exposure estimation presents a considerable challenge in occupational hygiene. The estimates must closely reflect past conditions, and there is often little historical information to guide the estimation process. Where historical data are absent and potential study subjects are deceased, exposure assessment methods include the use of job titles, individual exposure assessment by experts, and job-exposure matrices (1). For electrical utility workers exposed to extremely low-frequency (ELF) electric and magnetic fields (EMF), exposures only began to be documented in the late 1970s after reports of health effects in substation workers $(2,3)$. Earlier exposure data are rare. For the Canada-France study of cancer in electrical utility workers and ELF fields (4), we had used a job-exposure matrix (5) to estimate present exposures and had required a method of estimating past exposures that minimized subjectivity. The detailed exposure measurements made possible by personal ELF-EMF monitors $(6,7)$ allowed estimation of the intensity and duration of exposures for tasks. Thus a task-based time-weighted average (TWA) model was chosen as the basis for exposure reconstruction (8). To

1 Joint Departments of Epidemiology, Biostatistics and Occupational Health, McGill University, Montreal (QC), Canada.

2 Workers' Compensation Board of British Columbia, Prince George (BC), Canada.

3 Owens-Corning Canada, Candiac (QC), Canada.

4 Environmental Epidemiology Unit, London School of Hygiene and Tropical Medicine, London, United Kingdom.

Reprint requests to: Dr Jan-Erik Deadman, Carborundum-Kerlane, 17 Rue Antoine-Durafour, 42420 Lorette, France. [e-mail: jdeadm@ibm.net] 
determine how past exposures of electric utility workers in the province of Quebec were likely to have differed from the present, we reviewed 32 job categories for changes that might have substantially modified the intensities of ELF-EMF exposures or the durations of tasks. For jobs thought likely to have differed substantially from the present, we reconstructed exposures for the years 1945 to 1990 . The reconstruction consisted of a separate estimation of current intensities and durations of exposures for tasks and locations, followed by extrapolation to past conditions. In this report we present the estimation method and the results for job categories at the Quebec electrical utility, Hydro-Québec.

\section{Methods}

At the time of this study, the utility employed 22000 workers in 10 geographic regions and at its head offices. Interviews with workers in job categories exposed to ELF electric and magnetic fields were carried out in 4 distribution regions and 2 production regions, together accounting for $88 \%$ of the worksites of the subjects in the cancer study. Of the 32 job categories derived for the job-exposure matrix (5), we sought to identify those in which past exposures might have differed substantially from the measured 1990 values, for any 5-year period since 1940. Historical descriptions of jobs and equipment were first sought through annual reports, newsletters, and other technical documentation at the utility, with little success. The main source of information on past exposure durations and likely exposure intensities came from long-term employees.

\section{Estimation of current exposure intensities and durations for tasks or locations}

Exposures to ELF electric and magnetic fields result from tasks in which the worker is close to energized lines or equipment. Since these sources are usually in fixed locations such as generating stations, substations, or transmission line corridors, it is practical to classify tasks by their location. Generally, average exposure intensity for a given task in a given location will be similar between workers if the equipment and work procedures are similar. Location is also useful for grouping disparate activities for which the location and not the task primarily determines exposure intensity; this is the case for office work and activities such as lunch and coffee breaks.

For the job categories in which past exposures were judged as likely to have differed substantially from the measured 1990 values (table 1), the monitoring records of between 5 and 22 workers per category were randomly selected from those of all the measured workers. These records consisted of the minute-to-minute readings of
ELF magnetic and electric fields over a workweek, and the worker's log sheet (which gave start and stop times and task descriptions). For each task noted on the log sheet (or location if it was judged to dominate exposure), arithmetic mean ELF magnetic and electric fields were calculated and task durations were recorded with Positron meter software (5).

These estimates were classified into task categories by general types of activity or location and the voltage level when it had been noted (line loading had seldom been recorded). As weighted means were expected to be more representative and less variable than unweighted ones, the weighted means were calculated for each task or location category, with weights provided by the measurement times of the individual tasks. We calculated weighted means for the different voltage levels and for all the voltage levels combined. (An example for distribution linemen is shown in tables 2 and 3.) The calculation of confidence intervals that fully respect the weighting of measurements by time over which each measurement was made, and the highly skewed distribution both within and between measurements, is problematic (9). To estimate sampling variability, we used an approximate method for unweighted means of lognormally distributed values (10).

\section{Estimation of past exposure durations and intensities for tasks or locations}

During a 5-month period, about 100 long-term workers and retired employees at the utility were interviewed. To maximize collaboration, we first sought commitments from senior management. They enrolled regional managers and supervisors for the job categories and informed them of the goals of the study and the type of information required. Long-term workers were then questioned about the job titles used in the past, particularly specialization within the trade, changes in job duties and equipment over time, and changes in work locations and in time spent in different locations.

Estimation of past exposure durations. From the monitoring data, we prepared job profiles listing the task and location categories and the durations of time spent in them in 1990. The use of task categories simplified the reconstruction; during interviews workers were only required to comment on the categories instead of many individual tasks. Job profiles were presented to each group of workers asked to estimate the time spent in each task category over the years since 1945. To help the workers think about past conditions, we provided lists of the individual tasks within each task category and the average times spent at each location in 1990 . Between 1 and 13 interviews were carried out for most trades, with workers generally able to recall reliably 
Table 1. Overview of job categories considered for past reconstruction and the resulting exposure ratios. $(\mathrm{OH}=$ overhead, $U G=$ underground, $\mathrm{RCC} / \mathrm{DCC}=$ regional control center/distribution control center)

\begin{tabular}{|c|c|c|c|c|c|}
\hline \multirow[t]{2}{*}{ Job category } & \multirow[t]{2}{*}{$\begin{array}{l}\text { Key past differences identified } \\
\text { during interviews }\end{array}$} & \multirow{2}{*}{$\begin{array}{l}\text { Past exposure } \\
\text { likely to have } \\
\text { differed } \\
\text { substantially } \\
\text { from } 1990 \\
\text { values }\end{array}$} & \multirow{2}{*}{$\begin{array}{l}\text { Number of } \\
\text { worker } \\
\text { records } \\
\text { analyzed }\end{array}$} & \multicolumn{2}{|c|}{$\begin{array}{l}\text { Ratio of } 60-\mathrm{Hz} \text { fields } \\
\quad 1945: 1990\end{array}$} \\
\hline & & & & Magnetic & Electric \\
\hline \multicolumn{6}{|l|}{ Expected low-exposure job } \\
\hline $\begin{array}{l}\text { Blue-collar joba } \\
\text { White-collar job }\end{array}$ & $\begin{array}{l}\text { Expected low exposure } \\
\text { Expected low exposure }\end{array}$ & $\begin{array}{l}\text { No } \\
\text { No }\end{array}$ & ; & . & . \\
\hline \multicolumn{6}{|l|}{ Hydroelectric generation } \\
\hline $\begin{array}{l}\text { Equipment electrician } \\
\text { Equipment mechanic } \\
\text { Foreman, operations and others } \\
\text { Operator, hydrogenerating station }\end{array}$ & $\begin{array}{l}\text { Minor changes in sources \& tasks } \\
\text { Minor changes in sources \& tasks } \\
\text { Minor changes in sources \& tasks } \\
\text { Job titles and functions different in past }\end{array}$ & $\begin{array}{l}\text { No } \\
\text { No } \\
\text { No } \\
\text { Yes }\end{array}$ & 8 & $\dot{\cdot}$ & $\dot{5}$ \\
\hline \multicolumn{6}{|l|}{ Nuclear generation } \\
\hline $\begin{array}{l}\text { Equipment electrician } \\
\text { Operator, nuclear station }\end{array}$ & $\begin{array}{l}\text { No changes since inception in } 1983 \\
\text { No changes since inception in } 1983\end{array}$ & $\begin{array}{l}\text { No } \\
\text { No }\end{array}$ & . & . & : \\
\hline \multicolumn{6}{|l|}{ Diesel generation } \\
\hline Operator, autonomous network & No changes since inception & No & . & . & \\
\hline \multicolumn{6}{|l|}{ Transmission } \\
\hline $\begin{array}{l}\text { Forestry worker } \\
\text { Transmission splicer } \\
\text { Transmission lineman } \leq 735 \mathrm{kV}\end{array}$ & $\begin{array}{l}\text { No cases or referents } \\
\text { No cases or referents } \\
\text { Less "contact" work; lower voltages; } \\
\text { more time in right of way }\end{array}$ & $\begin{array}{l}\text { Not considered } \\
\text { Not considered } \\
\text { Yes }\end{array}$ & d & $\dot{.}$ & 0.84 \\
\hline \multicolumn{6}{|l|}{ Substation } \\
\hline Equipment electrician $\leq 735 \mathrm{kV}$ & $\begin{array}{l}\text { Lower amperages and voltages; more time } \\
\text { in substation }\end{array}$ & Yes & 11 & 0.55 & 0.69 \\
\hline $\begin{array}{l}\text { Equipment electrician } 735 \mathrm{kV} \text { substation } \\
\text { Maintanence worker, civil \& mechanical } \\
\text { engineer }\end{array}$ & $\begin{array}{l}\text { No changes since inception of this type of station } \\
\text { Lower amperages and voltages }\end{array}$ & $\begin{array}{l}\text { No } \\
\text { Yes }\end{array}$ & 6 & 0.42 & 0.59 \\
\hline Operator, mobile & $\begin{array}{l}\text { Lower amperages and voltages; more time } \\
\text { in substation }\end{array}$ & Yes & 13 & 0.53 & 0.88 \\
\hline $\begin{array}{l}\text { Operator, } 735 \mathrm{kV} \text { substation } \\
\text { Technician, automatic control/relay }\end{array}$ & $\begin{array}{l}\text { No changes since inception of this type of station } \\
\text { Lower amperages and voltages; more time } \\
\text { in substation }\end{array}$ & $\begin{array}{l}\text { No } \\
\text { Yes }\end{array}$ & 9 & 0.69 & 0.74 \\
\hline \multicolumn{6}{|l|}{ Distribution } \\
\hline Emergency man & $\begin{array}{l}\text { Lower voltage and current; recent job, } \\
\text { limited to } 2 \text { regions }\end{array}$ & Yes & 5 & 0.36 & 0.60 \\
\hline Foreman, $\mathrm{OH}$ lines & $\begin{array}{l}\text { Lower voltage and current; } \\
\text { more time in field in past }\end{array}$ & Yes & c & 0.92 & 2.01 \\
\hline Foreman, UG lines & $\begin{array}{l}\text { Lower voltage and current; } \\
\text { more time in field in past }\end{array}$ & Yes & c & 1.03 & 0.82 \\
\hline Lineman, contact and hotstick method & $\begin{array}{l}\text { Lower voltage and current; } \\
\text { more time on poles in past }\end{array}$ & Yes & 22 & 0.94 & 1.68 \\
\hline Lineman, contact method & $\begin{array}{l}\text { Lower voltage and current; } \\
\text { more time on poles in past }\end{array}$ & Yes & 15 & 0.82 & 1.13 \\
\hline Meter installer & $\begin{array}{l}\text { Lower voltage and current; } \\
\text { some time on poles in past }\end{array}$ & Yes & 5 & 0.47 & 1.00 \\
\hline Meter reader & $\begin{array}{l}\text { Industrial and residential meter readers } \\
\text { separate jobs in past; but unable to } \\
\text { differentiate from work histories }\end{array}$ & No & . & . & . \\
\hline Splicer, distribution & $\begin{array}{l}\text { Lower voltage and current; } \\
\text { more time in cable vault in past }\end{array}$ & Yes & 15 & 0.74 & 0.89 \\
\hline Tree trimmer & Now subcontracted & Yes & 5 & 0.49 & 0.68 \\
\hline \multicolumn{6}{|l|}{ Others } \\
\hline $\begin{array}{l}\text { Estimator } \\
\text { Instructor }\end{array}$ & $\begin{array}{l}\text { Less office work in past, but low exposure } \\
\text { Two groups in past (substations, others), } \\
\text { but low exposure }\end{array}$ & $\begin{array}{l}\text { No } \\
\text { No }\end{array}$ & . & . & . \\
\hline $\begin{array}{l}\text { Licensed electricians } \\
\text { Operator/dispatcher RCC/DCC }\end{array}$ & $\begin{array}{l}\text { Minor changes in sources and tasks } \\
\text { Formerly in substations, but unable } \\
\text { to differentiate from work histories }\end{array}$ & $\begin{array}{l}\text { No } \\
\text { No }\end{array}$ & . & : & . \\
\hline Technician, telecommunications & $\begin{array}{l}\text { No changes in sources and tasks, } \\
\text { and recent job category }\end{array}$ & No & . & . & \\
\hline
\end{tabular}

a Blue-collar jobs: clerk (accounting, judicial, mail, stores, data entry), meter inspector, storèkeeper, mechanic (vehicles and equipment), toolkeeper, technician (planning, management).

b White-collar jobs: agent, division head, section head, shift supervisor, consultant (systems management, personnel), engineer, commercial representative.

- Reconstructed from task exposures for linemen. 
Table 2. Task and location exposure estimates for Hydro-Québec distribution linemen (contact method)a, separated by voltage level.

\begin{tabular}{|c|c|c|c|c|c|c|c|}
\hline \multicolumn{2}{|c|}{ Task name } & \multirow{3}{*}{$\begin{array}{c}\begin{array}{c}\text { Number of } \\
\text { measurements }\end{array} \\
110\end{array}$} & \multirow{3}{*}{$\frac{\begin{array}{c}\text { Total } \\
\text { duration } \\
\text { (min) }\end{array}}{6350}$} & \multicolumn{2}{|c|}{ Electric $(\mathrm{V} / \mathrm{m})$} & \multicolumn{2}{|c|}{ Magnetic $(\mu T)$} \\
\hline & & & & \multirow{2}{*}{$\frac{A M w^{t b}}{3.62}$} & \multirow{2}{*}{$\frac{95 \% \mathrm{Cl}^{\mathrm{c}}}{2.34-5.60}$} & \multirow{2}{*}{$\frac{A M w g t^{b}}{0.18}$} & \multirow{2}{*}{$\frac{95 \% \mathrm{Cl}^{\mathrm{c}}}{0.15-0.21}$} \\
\hline 1 & Expected low-exposure work & & & & & & \\
\hline \multirow[t]{7}{*}{2} & Work done from bucket & & & & & & \\
\hline & Voltage not stated & 2 & 152 & 1289.67 & · & 27.81 & $0.00-8.05 E+10$ \\
\hline & (hookups) & 17 & 1425 & 88.20 & $35.64-218.27$ & 2.96 & $1.37-6.41$ \\
\hline & (dead-line, live-line) & 16 & 1855 & 252.15 & $47.76-1331.20$ & 0.56 & $0.37-0.86$ \\
\hline & $\begin{array}{l}\text { Primaries, } 12 \mathrm{kV} \\
\text { (gloves) }\end{array}$ & 17 & 2135 & 418.26 & $61.01-2867.22$ & 2.48 & $0.77-8.02$ \\
\hline & Primaries, $25 \mathrm{kV}$ & & & & & & \\
\hline & (gloves) & 10 & 974 & 1817.89 & $335.61-9846.87$ & 3.84 & $0.99-14.85$ \\
\hline 3 & Work done from pole & 3 & 291 & 100.65 & $2.98-3404.44$ & 0.25 & $0.14-0.44$ \\
\hline \multirow[t]{6}{*}{4} & Work on ground & & & & & & \\
\hline & $\begin{array}{l}\text { Groundman work } \\
\text { (voltage not stated) }\end{array}$ & 24 & 1862 & 8.89 & $4.57-17.32$ & 0.29 & $0.20-0.43$ \\
\hline & Groundman work & & & & & & \\
\hline & (under $12 \mathrm{kV}$ lines) & 3 & 208 & 13.93 & $0.41-469.23$ & 0.39 & $0.32-0.47$ \\
\hline & $\begin{array}{l}\text { Groundman work } \\
\text { (under } 25 \mathrm{kV} \text { lines) }\end{array}$ & 10 & 810 & 42.53 & $8.37-216.15$ & 0.62 & $0.31-1.27$ \\
\hline & Total exposure & 212 & 15912 & 223.58 & $98.96-505.11$ & 1.31 & $1.02-1.67$ \\
\hline
\end{tabular}

a Based on data from 15 workers sampled during July and August.

- Arithmetic mean weighted by duration of each task.

c Cox approximation for unweighted arithmetic mean.

o Includes office, garage, storeroom, transportation, meals and coffee breaks.

Table 3. Task and location exposure estimates for Hydro-Québec distribution linemen (contact method), all voltage levels combined.

\begin{tabular}{|c|c|c|c|c|c|c|}
\hline \multirow[t]{2}{*}{ Task name } & \multirow{2}{*}{$\begin{array}{l}\text { Number of } \\
\text { measurements }\end{array}$} & \multirow{2}{*}{$\begin{array}{l}\text { Total } \\
\text { duration } \\
\text { (min) }\end{array}$} & \multicolumn{2}{|c|}{ Electric $(\mathrm{V} / \mathrm{m})$} & \multicolumn{2}{|c|}{ Magnetic $(\mu T)$} \\
\hline & & & $A M w^{a} t^{a}$ & $95 \% \mathrm{Cl}$ & AM wgta & $95 \% \mathrm{Cl}$ \\
\hline $\begin{array}{l}1 \text { Expected low-exposure work } \\
2 \text { Work from bucket } \\
3 \text { Work from pole } \\
4 \text { Work on ground }\end{array}$ & $\begin{array}{r}110 \\
62 \\
3 \\
37\end{array}$ & $\begin{array}{r}6350 \\
6391 \\
291 \\
2880\end{array}$ & $\begin{array}{r}3.62 \\
540.04 \\
100.65 \\
18.72\end{array}$ & $\begin{array}{c}2.34-5.60 \\
186.57-1563.22 \\
2.98-3404.44 \\
9.89-35.41\end{array}$ & $\begin{array}{l}0.18 \\
2.89 \\
0.25 \\
0.39\end{array}$ & $\begin{array}{l}0.15-0.21 \\
1.74-4.80 \\
0.14-0.44 \\
0.28-0.54\end{array}$ \\
\hline Total exposure & 212 & 15912 & 223.58 & $98.96-505.11$ & 1.31 & $1.02-1.67$ \\
\hline
\end{tabular}

a Arithmetic mean weighted by duration of each task.

times spent at different tasks or locations. Transmission linemen and mobile substation operators, however, could not reliably describe the time spent near lines of different voltage levels, which could differ widely for a given task.

Estimation of past exposure intensities. The intensity of a utility worker's exposure to ELF fields from energized conductors depends on the number of conductors, their current, voltage, geometry and phasing, and the worker's proximity. The increased demand for electricity over the years has been met by the addition of transmission and distribution circuits and increases in line loading and voltage. These increases are expected to have increased magnetic and electric fields near the lines; exposure intensities will have increased if distances between workers and sources have remained the same. Thus, for each job category, experts from the utility and long-term workers were asked to review past changes in equipment, work practices, and locations and judge the effect each change might have had on exposure. We obtained historical records of transmission line lengths, voltages, and durations of maintenance work for 5 time points since 1925 , but were unable to obtain records of line loadings, substation capacities, or the numbers of substations in the past. Shortly after completing the study, we obtained limited information on the historical levels of power production that, with the historical transmission line data, were used to estimate mean loadings on transmission lines; these results are reviewed in the discussion.

Given the limited amount of historical data on the changes in the transmission and distribution network, we judged that the most reliable method to determine past exposure intensities was to extrapolate from current exposure measurements (5). Past exposure intensities that fit the descriptions of system changes best were extrapolated from these data, with some reasonable assumptions about field levels in the past. 


\section{Reconstruction of profiles for past periods}

After completing the interviews, we tabulated current and past estimates of mean intensities and durations of exposures for tasks and locations for 5- or 10-year intervals, to calculate a TWA for the interval. Table 4 illustrates the reconstruction of magnetic fields, with distribution linemen as the example. The data in the last column (1990) of table 4 are the measured intensity and duration values from a sample of workers. Duration data for earlier years are from interviews, and intensity data have been extrapolated from the 1990 values according to knowledge of system changes. The 4 task or location categories were "expected low exposure" (all tasks performed under documented low magnetic, eg, $\leq 0.2 \mu \mathrm{T}$, fields), "work from bucket" (all tasks performed from the insulated bucket), "work from pole" (all tasks performed while attached to the pole), and "work on ground" (all tasks performed while on the ground underneath or near the distribution lines). For jobs that had disappeared before 1990, past exposures were reconstructed by combining exposure intensity data from comparable tasks in other jobs, with time estimates obtained from interviews.

As the calculated past TWA exposures for the job categories were based on data from a subsample of workers from the categories, they were not used directly in the epidemiologic study. Instead, the ratios of the TWA exposure for each past period over the TWA exposure for 1990 were used. For the epidemiologic study, the measured mean magnetic (or electric) field for a job category was multiplied by the ratio for each past period.

\section{Results}

Of the 32 job categories reviewed, 14 were judged likely to have had past exposures to either $60-\mathrm{Hz}$ electric or magnetic fields substantially different from those measured in 1990 . The last column of table 1 shows the ratio of estimated TWA fields in 1945 to that in 1990. Among the 14 job categories, magnetic field exposures were estimated to have increased the most over time for job categories of working in substations and on distribution lines. Magnetic field exposures for the 2 jobs in generation and transmission that were reconstructed were estimated to have increased very little. For the substations, the ratio of magnetic fields in the period 1945-1949 to those in 1985-1990 ranged from 0.42 to 0.69 for the 4 job categories. Of the 8 jobs involved in the distribution of electricity, all but one showed increases in magnetic field levels over time, the 1945:1990 ratios ranging from 0.36 to 0.94 . For electric fields in substations, the estimated increase over time was not as steep as for magnetic fields; ratios of fields in 1945 and 1990 ranged from 0.59 to 0.88 . For the distribution line jobs, past electric field exposures were judged as lower than in 1990 in 4 cases (1945:1990 ratios: 0.6 to 0.89 ), higher in 3 others (1945:1990 ratios: 1.13 to 2.01 ) and unchanged in 1 . Figures 1 and 2 show the magnetic and electric field estimates for the 14 job categories as a function of time.

Except for the hydroelectric generating station operators, all of the 14 jobs were carried out in 1 of 3 work environments: transmission lines, distribution lines, or substations. A review of the changes in these environments follows to illustrate how the intensities and durations of past exposures were estimated for the jobs within them.

\section{Transmission line jobs}

Of the 3 transmission line job categories (table 1) only transmission linemen appeared in the list of jobs held by subjects of the cancer study. Tasks and work locations have changed little over time: linemen patrol, inspect

Table 4. Calculation of ratios for past exposures to $60-\mathrm{Hz}$ magnetic fields; distribution linemen (contact method).

\begin{tabular}{|c|c|c|c|c|c|c|c|c|c|c|c|c|c|c|}
\hline \multirow[t]{2}{*}{ Task/location } & \multicolumn{2}{|c|}{$1940-1949$} & \multicolumn{2}{|c|}{$1950-1959$} & \multicolumn{2}{|c|}{$1960-1964$} & \multicolumn{2}{|c|}{$1965-1969$} & \multicolumn{2}{|c|}{$1970-1974$} & \multicolumn{2}{|c|}{$1975-1989$} & \multicolumn{2}{|c|}{1990} \\
\hline & $\begin{array}{l}\text { Hours/ } \\
\text { week }\end{array}$ & $\begin{array}{l}\text { Magnetic } \\
\text { fields } \\
(\mu \mathrm{T})\end{array}$ & $\begin{array}{l}\text { Hours/ } \\
\text { week }\end{array}$ & $\begin{array}{l}\text { Magnetic } \\
\text { fields } \\
(\mu \mathrm{T})\end{array}$ & $\begin{array}{l}\text { Hours/ } \\
\text { week }\end{array}$ & $\begin{array}{l}\text { Magnetic } \\
\text { fields } \\
(\mu \mathrm{T})\end{array}$ & $\begin{array}{c}\text { Hours/ } \\
\text { week }\end{array}$ & $\begin{array}{l}\text { Magnetic } \\
\text { fields } \\
(\mu \mathrm{T})\end{array}$ & $\begin{array}{l}\text { Hours/ } \\
\text { week }\end{array}$ & $\begin{array}{l}\text { Magnetic } \\
\text { fields } \\
(\mu T)\end{array}$ & $\begin{array}{l}\text { Hours/ } \\
\text { week }\end{array}$ & $\begin{array}{l}\text { Magnetic } \\
\text { fields } \\
(\mu T)\end{array}$ & $\begin{array}{l}\text { Hours/ } \\
\text { week }\end{array}$ & $\begin{array}{c}\text { Magnetic } \\
\text { fields } \\
(\mu T)\end{array}$ \\
\hline $\begin{array}{l}\text { Expected low } \\
\text { exposure }\end{array}$ & 10 & 0.13 & 10 & 0.13 & 10 & 0.14 & 10 & 0.15 & 16.5 & 0.16 & 18 & 0.18 & 18 & 0.2 \\
\hline $\begin{array}{l}\text { Work from } \\
\text { bucket }\end{array}$ & 0 & & 0 & . & 0 & . & 0 & & 7 & 2.89 & 13.5 & 2.89 & 13.5 & 2.89 \\
\hline $\begin{array}{l}\text { Work from } \\
\text { pole }\end{array}$ & 35 & 1.25 & 31 & 1.25 & 27.5 & 1.5 & 27.5 & 1.75 & 10 & 2 & 0.5 & 0.25 & 0.5 & 0.25 \\
\hline $\begin{array}{l}\text { Work on } \\
\text { ground }\end{array}$ & 5 & 0.24 & 5 & 0.24 & 5.5 & 0.28 & 5.5 & 0.32 & 8.5 & 0.36 & 8.5 & 0.39 & 8.5 & 0.39 \\
\hline $\begin{array}{l}\text { Total h/week } \\
\text { Time-weighted } \\
\text { average }(\mu \mathrm{T})\end{array}$ & 50 & 0.93 & 46 & 0.90 & 43 & 1.03 & 43 & 1.20 & 42 & 1.09 & 40.5 & 1.13 & 40.5 & 1.13 \\
\hline $\begin{array}{l}\text { Ratio to. } \\
1990\end{array}$ & . & 0.82 & & 0.79 & & 0.91 & . & 1.06 & & 0.97 & . & 1.00 & . & 1.00 \\
\hline
\end{tabular}



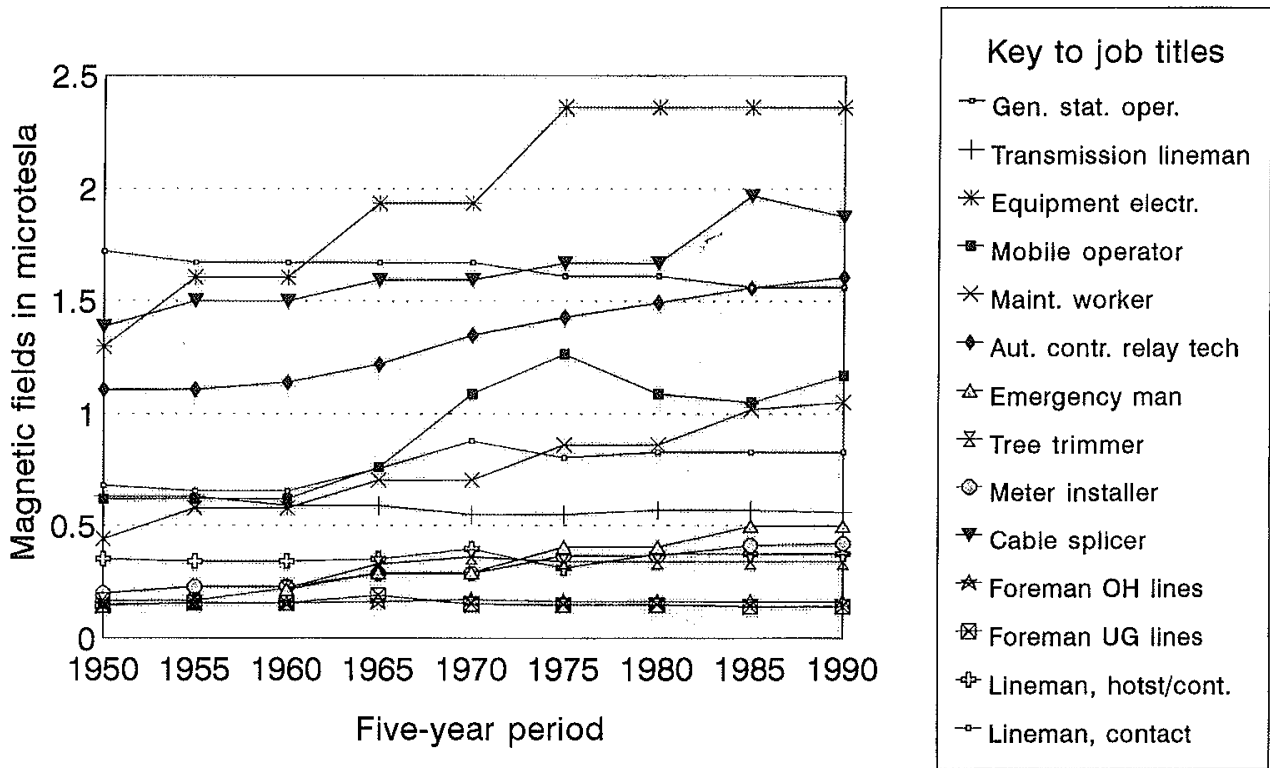

Figure 1. Estimated evolution of 60-Hz magnetic fields at Hydro-Québec, 1950-1990 generation, transmission, substation and distribution jobs.
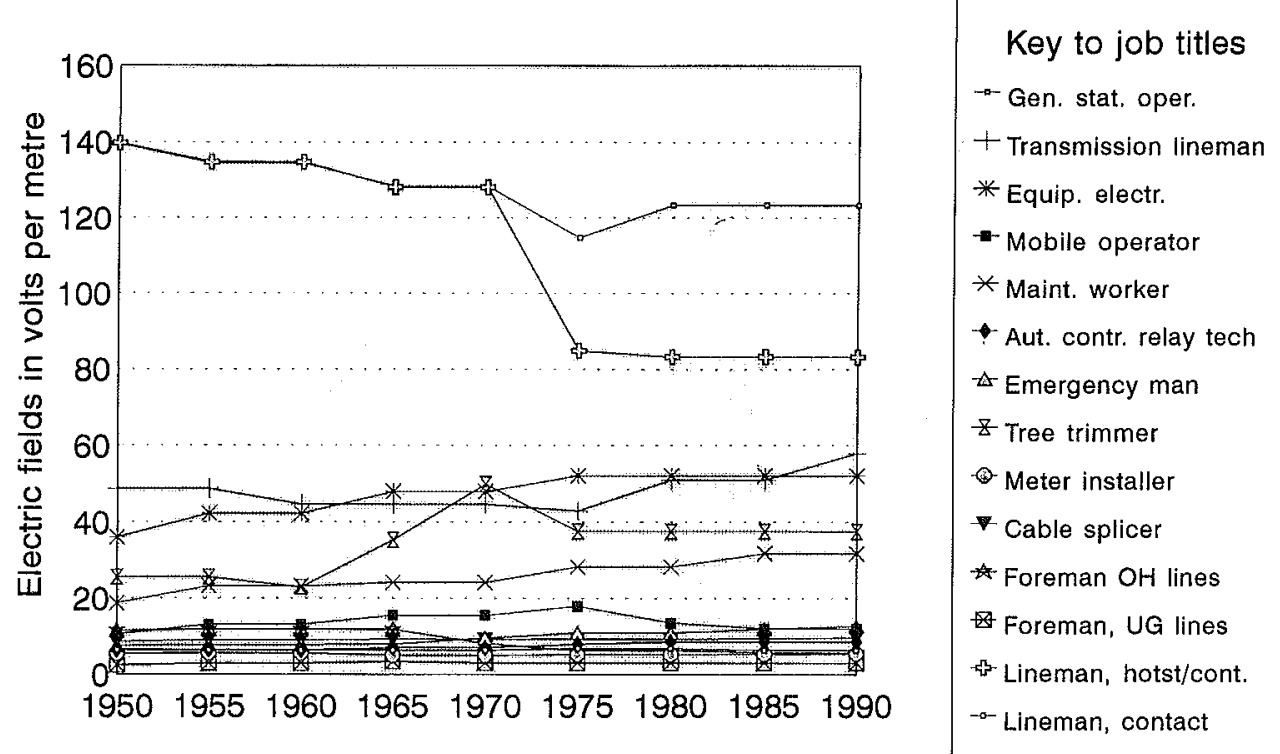

Figure 2. Estimated evolution of 60-Hz electric fields at Hydro-Québec, 1950-1990 generation, transmission, substation and distribution jobs.

and service high-voltage transmission lines (44 to $765 \mathrm{kV}$ ), service telecommunication towers, and, in the past, cleared vegetation from the rights-of-way. Modern use of all-terrain vehicles, snowmobiles, and helicopters has reduced the time linemen spend in the rights-of-way. Work on energized lines (live-line) is now more common than in the past and is done either with the "hot stick" method (insulated rod) or with the "contact" method (insulated glove). In the latter case, linemen work at arms' length or closer to the conductors. As the interviewed workers were unable to define the proportion of live-line work or the breakdown between hot stick and contact work clearly, we did not attempt to adjust for these changes in our estimates of past exposure intensities. Transmission line voltages have been steadily increasing over the years (table 5). The current capacity of lines has also increased, but records of line loading were not available. In summary, linemen in the past were exposed to lower voltages, possibly less current on conductors, and used the contact method less. On the other hand, they spent more time in the rights-of-way in the past. 
Table 5. Growth of electrical transmission lines in Québec.

\begin{tabular}{|c|c|c|c|c|c|c|c|c|c|}
\hline \multirow[t]{3}{*}{ Year } & \multicolumn{8}{|c|}{ Kilometers of transmission lines } & \multirow{3}{*}{$\begin{array}{c}\text { Total person-years } \\
\text { of inspection, } \\
\text { maintenance } \\
\text { and repair }\end{array}$} \\
\hline & \multicolumn{7}{|c|}{ Voltage (kV) } & \multirow{2}{*}{$\begin{array}{l}\text { Total line } \\
\text { length }\end{array}$} & \\
\hline & 44 & 69 & 120 & 161 & 230 & 300 & 735 & & \\
\hline 1906 & - & 53 & - & - & - & - & - & 53 & 1.04 \\
\hline 1911 & - & 54 & 37 & - & - & - & - & 91 & 1.29 \\
\hline 1917 & 48 & 188 & 48 & - & - & 一 & - & 284 & 3.92 \\
\hline 1925 & 100 & 231 & 48 & - & 108 & - & - & 487 & 5.79 \\
\hline 1955 & 589 & 947 & 2165 & 404 & 1241 & 282 & - & 5628 & 46.33 \\
\hline 1965 & 591 & 2093 & 3184 & 712 & 2004 & 2042 & 640 & 11266 & 79.24 \\
\hline 1986 & 656 & 2880 & 5853 & 1504 & 3038 & 3796 & 10175 & 27902 & 176.27 \\
\hline 1991 & 656 & 2904 & 5998 & 1584 & 3042 & 3859 & 10175 & 28218 & 240.44 \\
\hline
\end{tabular}

To estimate the past intensity of linemen's exposures by task, we separated the monitoring data by line voltage. Electric fields for a given voltage of line were assumed not to have changed over time. For magnetic fields, we did not have data on average line loads, or overall loading of the network. We judged that increases in the loading of the transmission line network were likely to have been offset by the addition of circuits, and thus we did not adjust the estimates of magnetic field intensity.

As workers had expressed difficulty in recalling the time spent at each voltage level, we considered using the records of transmission line length and time spent inspecting, servicing, and repairing lines (table 5) as a guide. Comparison of the time data with the total length of transmission lines showed a clear increase over the years as the total length of transmission line circuits had increased $(r=0.97)$. Accordingly, the total length of lines at each voltage level was used as a surrogate for the time that would have been spent inspecting, servicing, and repairing the line.

\section{Transformer substations}

Four of the 6 substation job categories were considered for past extrapolation (table 1). As the $735-\mathrm{kV}$ substations were new, the tasks and locations of electricians and operators in them were judged to have changed little over time. Typically, substations consist of a high-voltage supply section and 2 lower voltage output sections. During the $1950 \mathrm{~s}, 60 \mathrm{kV}$ and $12 \mathrm{kV}$ were the most common voltage levels. In $1990,120 \mathrm{kV}$ and $69 \mathrm{kV}$ were the most common, the $69-\mathrm{kV}$ substations gradually being shut down. When a substation reaches capacity, extra circuits and equipment are built, causing the station to expand in area. Expansion alone will not necessarily have increased magnetic field exposures, unless the load on individual circuits has also increased. Since conductor spacing and clearance differ for different voltage sections, upgrading to higher voltage levels may not have increased electric field exposures in proportion to the voltage level. Generally, exposures in substations in the past were likely to have been lower than 1990 values due to lower substation loadings, and lower voltages. For apparatus electricians, mobile operators, and technicians, the lower intensities may have been offset by the longer times spent in the substations in the past. Maintenance workers, whose time in substation yards has changed little, are likely to have had lower exposures.

As we were unable to obtain historical data on the number and types of substations or typical substation loadings, our estimates of substation electric and magnetic fields were based on the monitoring data. The electric field exposures in substation yards showed some association with voltage for mobile operators only $(\mathrm{r}=0.34)$. Magnetic fields showed strong dependence on substation voltage for mobile operators $(r=0.88)$, but not for the other jobs (data not shown). Considering all the changes in substations over the years, and using present levels in $69 \mathrm{kV}$ substations as a guide, we estimated the magnetic and electric field intensities for the 1950 s as one-half of the 1990 values.

\section{Distribution lines}

Except for meter readers, past exposures of all the distribution line job categories were considered as likely to have differed from current levels (table 1). The results for distribution linemen, a trade that has undergone considerable change over the years, are presented as an example for distribution line jobs in general. These linemen repair and construct overhead electrical distribution lines of medium voltages $(2.4$ to $34.5 \mathrm{kV})$ and low voltages $(\leq 750 \mathrm{~V})$. Before the $1970 \mathrm{~s}$, linemen worked in 1 of 2 distinct exposure subgroups: linemen (worked directly with the lines from the pole) and groundmen (prepared materials or coordinated work on the ground). Modern distribution linemen work in smaller teams and rotate their work, with no distinction between linemen and groundmen. Foremen are no longer on the job site, most of their duties having been transferred to the senior linemen. 
Before 1960, the dominant voltage in the overhead distribution network was $4 \mathrm{kV}$, with maximum amperages typically between 200 and $300 \mathrm{~A}$. In the early $1960 \mathrm{~s}$ to the early $1970 \mathrm{~s}$, the $4-\mathrm{kV}$ lines were gradually converted to $12 \mathrm{kV}$, with maximum amperages near $400 \mathrm{~A}$. From the late $1960 \mathrm{~s}$ on, lines were converted to $25 \mathrm{kV}$, with maximum amperages near 500 to $600 \mathrm{~A}$. During the late 1970s, massive conversion to electric residential heating led to a large increase in the electricity being carried by distribution lines. The size of conductors increased to keep up with the demand for electricity, and transformers became more numerous and larger than in the past. More work is presently done on de-energized lines now that lines can be isolated in more places than in the past. Up until the early 1960 s, rubber gloves were used for live line work up to $4 \mathrm{kV}$; higher voltage lines were de-energized. The distribution linemen estimated that in 1945-1949 their trade spent an average 35 hours a week working from the pole (table 3 ). The arrival of the bucket truck in the early 1970 s greatly reduced the need to climb poles and allowed routine tasks to be done more rapidly. By 1970 the average time spent up on the pole was estimated as 10 hours, and in 1975 as 30 minutes when the change to bucket trucks was complete. In parallel, the quality of rubber gloves was improved to the point where lines up to $34 \mathrm{kV}$ could be handled. Linemen in most regions of the utility alternated between the contact and hot stick method. Overall, several factors would have made past exposures higher than the measured 1990 values: more work on the poles, less use of hot sticks, more time spent close to the wires, and fewer places to isolate lines. Factors that will have reduced past exposures compared with 1990 include lower voltages, less service work, lower amperage on primary and secondary lines, and fewer transformers.

To derive estimates of magnetic and electric field intensities, we separated the monitoring data according to voltage level (table 2). The measured field intensities were used as a base line in assigning exposures for past periods, adjusting upwards or downwards to reflect changes in work methods and the dominant line voltages at the time. Historical information on line loading or on line lengths at each voltage level were not available. In our discussions with utility managers and senior workers, most of the men estimated that the average loadings on lines had increased by a factor of about 2 since the 1950s. Thus, for work on distribution lines and in distribution cable vaults, we used one-half of the 1990 value for magnetic fields as a base line for field intensities in 1950. Given the increases in distribution line currents over the years and the changes in work methods, the 1945 value for the intensity of average exposures during pole work was estimated as about $40 \%$ of the 1990 value for bucket work. We estimated ground work exposures in 1945 as about $60 \%$ of the 1990 values.

\section{Discussion}

To overcome limitations imposed by the scarcity of historical records, we reconstructed exposures to $60-\mathrm{Hz}$ magnetic and electric fields based on detailed knowledge of tasks. The reconstruction relied on 3 sources of information about tasks: measured present exposures, estimated past durations, and extrapolated past intensities derived from the measurements. Of 32 job categories at the utility, exposures in 18 were not adjusted for past conditions. Two of these (forestry workers, transmission cable splicers) had high electric or magnetic field exposures, but were not considered for adjustment because they did not appear in the list of jobs held by the cases or the referents of the epidemiologic study. The work environment of these 2 categories has always been the transmission line corridor, in which it was judged (see earlier discussion and that which follows) that past exposures were unlikely to have differed substantially from those measured in 1990 (5). The operators-dispatchers of the regional and distribution control centers were not considered for readjustment because the job histories did not specify worksites. Similarly, meter readers in the past were either industrial or residential meter readers, but the work histories did not specify sites. The remaining job categories were not considered for readjustment because we could find no evidence of changes that were likely to have substantially altered exposures, or we expected the exposure to be low. Low exposures were expected for estimators and instructors, office workers, and blue-collar workers in buildings not located near generation, transmission or distribution facilities. We judged that adjusting an already low exposure would not have substantially changed the results of the epidemiologic study, and we consequently excluded these jobs.

We designed this retrospective exposure assessment to reduce the subjectivity of past exposure estimation. This reduction was achieved by basing estimations on measured durations and intensities of task exposures from randomly selected workers and by restricting subjective opinion largely to the estimation of past task durations. The validity of the past exposure estimates cannot be directly verified, as no historical exposure measurements are available with which to make comparisons. Dosemici et al have described a method for indirectly validating retrospective exposure estimates (11), but it requires that the exposure be a risk factor for cancer, which remains unclear for ELF fields. The estimates derived for past TWA exposures will have been the most sensitive to past task estimates in which the products of intensity and duration dominated the TWA exposure. Systematic documentation of line loadings and substation types would improve our confidence in these estimates at the utility. Due to time constraints, we interviewed but a few experts in engineering and systems control. Furthermore, 
the lack of records describing system changes over time limited our ability to estimate past intensities of magnetic and electric fields for substations and distribution lines. After completing the reconstruction process, however, we were able to obtain partial historical information on power generated by the utility that, with the data described previously, allowed an approximation of the average historical loading on transmission lines. To reestimate how magnetic fields might have changed over time as current loading on transmission lines increased, we estimated average current loads for 1954 and for 1990 according to the following model:

$$
\bar{I} \cong P \times(n \bar{V})^{-1}
$$

where $\overline{\mathrm{I}}$ is the mean current, $P$ is the power generated, $n$ is the number of circuits, and $\bar{V}$ is the weighted mean transmission line voltage (weighted by length of line at each voltage). Here, $n$ is approximated by the total circuit length of the transmission line network. Over the 1954 to 1990 period, the weighted mean line voltage increased by a factor of $2.5(141$ to $350 \mathrm{kV})$, the total circuit length increased by a factor of 5.4 (6374 to 34193 $\mathrm{km}$ ), and power generated increased by a factor of 14.4 ( 8000 to $115000 \mathrm{MkWh}$ ). The increase in circuit length offset the increases in generated power and voltage and yielded a ratio of 1.08 for the mean currents in 1990 over 1954. This result provided support for our decision not to reduce past magnetic field intensities for transmission linemen.

Our estimates of historical exposure intensities in substations and near distribution lines could not be verified in this manner, as supplemental data were not available. However, comparison with the results from Ontario Hydro $(\mathrm{OH})$ which had historical data on transformer loadings in 1950 and 1990 (12), can provide some insight. Over this period, overall loading on $\mathrm{OH}$ substations was estimated to have increased by a factor of 4.6 , while total energy divided by the number of stations had increased by a factor of 2.7 . The average (3.7) of these 2 factors was used as an estimate of the average increase in magnetic fields in $\mathrm{OH}$ substations. Over that period, power generated in Ontario had increased by a factor of 9.1 (from 15900 to $145000 \mathrm{M}$ $\mathrm{kWh}$ ). At Electricite de France, the square-root of power consumption was used as an approximation of the increase in magnetic field levels over time (13). If this form of approximation is applied to the $\mathrm{OH}$ data, an estimated 3-fold increase in magnetic fields is obtained; applying it to the 19-fold increase in the amount of power generated in Quebec between 1950 and 1990 (5922 to $115000 \mathrm{MkWh}$ ) suggests an approximate 4-fold increase in Hydro-Quebec's substation magnetic fields. Thus our estimate of a 2 -fold increase in substation magnetic fields may have been conservative. For electric fields our estimate of a 2 -fold increase be- tween 1950 and 1990 is identical to that of Ontario Hydro.

\section{Concluding remarks}

This method of retrospective estimation of ELF-EMF exposure possesses several advantages. It allows separate estimation of the effects of changes to the duration and intensity of exposures. It relies on measured durations of time spent at tasks and work locations and also on measured exposure intensities. Furthermore, interviewed workers are only required to comment on the past durations of tasks. The main limitations in this application of the method were the small sample sizes and poor documentation of system changes at the utility. The method described can apply to contexts other than electrical utilities, if exposure intensities are measured at the level of tasks and the durations of tasks are estimated. Extrapolating exposures for tasks is simpler than for jobs, as the complexity of dealing with task durations is removed to be dealt with separately. Finally, a simple modification of the described method, in which workers keep logs of the durations of tasks they perform over several weeks, can improve the accuracy of long-term exposure estimates (14).

\section{Acknowledgments}

We sincerely thank all those at Hydro-Québec who helped with this study: the workers, foremen, and managers whom we interviewed; the retired employees who graciously participated; the people at the head office who helped us in identifying key persons (Camille Gaudreault, Robert Paul-Hus, Emmanuel Touchette, and René Leblanc of direction distribution, Jean-Claude Roy, Ghislain Ouellet, Clément Ouellet, Marc Charest, Paul Bourassa, Denis Champagne, Hubert Charbonneau, Louis Mauger and Yvon Perron of production, Transport et Télécommunication); and all others whose names we may have overlooked.

Financial support was provided by Hydro-Québec.

\section{References}

1. Goldberg M, Hémon D. Occupational epidemiology and assessment of exposure. Int J Epidemiol 1993;22 suppl 2:85s9.

2. Asanova TP, Rakov AM. Health conditions of workers exposed to electrical fields on open switchboard installations of $400-500 \mathrm{kV}$ : preliminary report. Gig Tr Prof Zabol $1966 ; 10: 50-2$. 
3. Korobkova V, Mozorov Y, Stolarov M, Yakub Y. Influence of the electric field in 500 and $750 \mathrm{kV}$ switchyard on maintenance staff and means for its protection. Presented at the Conference on Large High Voltage Electric Systems, $28 \mathrm{Au}-$ gust - 6 September 1972. Paper 23-06.

4. Thériault $\mathrm{G}$, Goldberg $M$, Miller $A B$, Armstrong $B$, Guénel $P$, Deadman $J$, et al. Cancer risks associated with occupational exposure to magnetic fields among electric utility workers in Ontario and Quebec, Canada, and France: 1970-1989. Am J Epidemiol 1994;139:550-72.

5. Deadman J-E, Armstrong, BG, Thériault GP. Exposures to 60-Hz magnetic and electric fields at a Canadian electric utility. Scand J Work Environ Health 1996;22:415-24.

6. Heroux PA dosimeter for assessment of exposures to ELF fields. Bioelectromagnetics 1991;12:241-57.

7. Bracken TD, Rankin FR, Senior RS, Alldredge JR, Sussman SS. Magnetic field exposure among utility workers. Bioelectromagnetics 1995;16:216-26.

8. Smith TJ, Hammond SK, Hallock M, Woskie SR. Exposure assessment for epidemiology: characteristics of exposure. Appl Occup Environ Hyg 1991;6:441—7.

9. Smith RW, Sahl JD, Kelsh MA, Zalinski J. Task-based exposure assessment: analytical strategies for summarizing data by occupational groups. Am Ind Hyg Assoc J 1997;58:408-16.

10. Armstrong BG. Confidence intervals for arithmetic means of lognormally distributed exposures. Am Ind Hyg Assoc $\mathrm{J} ; 53: 481-5$.

11. Dosemeci M, McLaughlin JK, Chen JQ, Hearl F, McCawley $\mathrm{M}, \mathrm{Wu} \mathrm{Z}$, et al. Indirect validation of a retrospective method of exposure assessment used in a nested case-control study of lung cancer and silica exposure. Occup Environ Med 1994; 51:136-8.

12. Donnelly KE. Occupational epidemiological study: retrospective adjustments to magnetic and electric field exposures. Montréal: Hydro-Québec, 1992. Final report of the Joint Electricité de France - Hydro-Quebec - Ontario Hydro epidemiological study on the long-term effects of exposure to 50 and $60-\mathrm{Hz}$ electric and magnetic fields.

13. Electricité de France / INSERM. Méthode d'attribution des coefficients correcteurs afin d'évaluer l'exposition passée aux champs électriques et magnétiques. Montréal: Hydro-Québec, 1992. Final report of the Joint Electricité de France - HydroQuebec - Ontario Hydro epidemiological study on the longterm effects of exposure to 50 and $60-\mathrm{Hz}$ electric and magnetic fields.

14. Olsen E. Analysis of exposure using a logbook method. Appl Occup Environ Hyg 1994;9:712—22.

Received for publication: 18 February 1997 